\title{
Bidirectional remodeling of $\beta 1$-integrin adhesions during chemotropic regulation of nerve growth
}

\author{
Lucas P Carlstrom', Jacob H Hines ${ }^{2,4}$, Steven J Henle ${ }^{2}$ and John R Henley ${ }^{2,3^{*}}$
}

\begin{abstract}
Background: Chemotropic factors in the extracellular microenvironment guide nerve growth by acting on the growth cone located at the tip of extending axons. Growth cone extension requires the coordination of cytoskeleton-dependent membrane protrusion and dynamic adhesion to the extracellular matrix, yet how chemotropic factors regulate these events remains an outstanding question. We demonstrated previously that the inhibitory factor myelin-associated glycoprotein (MAG) triggers endocytic removal of the adhesion receptor $\beta 1$ integrin from the growth cone surface membrane to negatively remodel substrate adhesions during chemorepulsion. Here, we tested how a neurotrophin might affect integrin adhesions.

Results: We report that brain-derived neurotropic factor (BDNF) positively regulates the formation of substrate adhesions in axonal growth cones during stimulated outgrowth and prevents removal of $\beta 1$-integrin adhesions by MAG. Treatment of Xenopus spinal neurons with BDNF rapidly triggered $\beta 1$-integrin clustering and induced the dynamic formation of nascent vinculin-containing adhesion complexes in the growth cone periphery. Both the formation of nascent $\beta 1$-integrin adhesions and the stimulation of axon extension by BDNF required cytoplasmic calcium ion signaling and integrin activation at the cell surface. Exposure to MAG decreased the number of $\beta 1$ integrin adhesions in the growth cone during inhibition of axon extension. In contrast, the BDNF-induced adhesions were resistant to negative remodeling by MAG, correlating with the ability of BDNF pretreatment to counteract MAG-inhibition of axon extension. Pre-exposure to MAG prevented the BDNF-induced formation of $\beta 1$ integrin adhesions and blocked the stimulation of axon extension by BDNF.

Conclusions: Altogether, these findings demonstrate the neurotrophin-dependent formation of integrin-based adhesions in the growth cone and reveal how a positive regulator of substrate adhesions can block the negative remodeling and growth inhibitory effects of MAG. Such bidirectional remodeling may allow the growth cone to rapidly adjust adhesiveness to the extracellular matrix as a general mechanism for governing axon extension. Techniques for manipulating integrin internalization and activation state may be important for overcoming local inhibitory factors after traumatic injury or neurodegenerative disease to enhance regenerative nerve growth.
\end{abstract}

\section{Background}

Neurons form targeted synaptic connections during embryonic development of the nervous system. Dysfunction of this wiring can lead to severe neurologic disorders, including schizophrenia [1], autism [2] and mental retardation [3]. To make precise connections, neuron cell bodies project axons that navigate the environment to reach appropriate targets $[4,5]$. The axonal growth cone guides this pathfinding by detecting multiple

\footnotetext{
* Correspondence: Henley.John@mayo.edu

${ }^{2}$ Department of Neurologic Surgery, Mayo Clinic: College of Medicine,

Rochester, Minnesota 55905, USA

Full list of author information is available at the end of the article
}

diffusible and substrate bound cues; transducing guidance signals; and dynamically coordinating local responses that include rapid membrane retrieval and insertion events, the activation of cytoskeleton-dependent membrane protrusion and substrate adhesion machinery [6-10]. Inhibition of axon outgrowth and disrupted rewiring of synaptic connections underlies the inability of the central nervous system to functionally regenerate after injury $[11,12]$. The potent inhibitory factor myelin-associated glycoprotein (MAG), which is released after nervous system injury [13-15], was found recently to negatively regulate growth cone adhesions [16]. Remarkably, the growth inhibitory factors
C Biomed Central

() 2011 Carlstrom et al; licensee BioMed Central Ltd. This is an Open Access article distributed under the terms of the Creative Commons Attribution License (http://creativecommons.org/licenses/by/2.0), which permits unrestricted use, distribution, and reproduction in any medium, provided the original work is properly cited. 
semaphorin 3A [17,18], Nogo-A [19,20] and chondroitin sulfate proteoglycans $[21,22]$ also disrupt growth cone adhesions by distinct mechanisms. In general, the negative remodeling of adhesions by growth inhibitory cues can occur by dismantling adhesion complexes, by deactivating and internalizing integrin adhesion receptors and by inhibiting adhesion-dependent signaling [23-26].

Integrins are type I transmembrane receptors that function as intermediaries between extracellular matrix components and the actin cytoskeleton $[27,28]$. $\beta 1$ integrin is highly expressed in motor and sensory neurons during development, but levels steadily decline into adulthood [29,30], where some expression is maintained for synaptic plasticity and stability [31]. Accumulating evidence indicates that integrins play an essential role in axon outgrowth and may serve as an important target for regenerative strategies [32-35]. Integrin receptors function bidirectionally through 'inside-out' and 'outside-in' mechanisms. Rearrangement of the integrin headpiece to a higher affinity ligand-binding state, known as integrin activation, is referred to as insideout' signaling. Stimulating clustering in sphingolipid microdomains within the plasma membrane also increases integrin receptor avidity [36,37]. Intracellular signaling cascades initiated through integrin-ligand interactions refer to an 'outside-in' mechanism. Both inside-out and outside-in functions are mediated through cytoplasmic adhesion components. Integrinbased adhesion complexes consist of membrane-cytoskeletal and signaling proteins, such as vinculin, which acts to couple integrin receptors to actin filaments [38,39], talin, which induces integrin activation [40-42] and focal adhesion kinase (FAK), which phosphorylates various targets and regulates dynamic adhesion turnover to stimulate growth cone migration $[25,43,44]$.

Neurotrophins are target-derived secreted factors that bind cognate Trk receptors expressed by the growth cone to promote neuron survival, differentiation, axon growth and synaptic plasticity [45-48]. The neurotrophin brain-derived neurotrophic factor (BDNF) binds and activates the receptor tyrosine kinase TrkB to control cytoskeletal rearrangements, membrane protrusion and growth cone motility [49-51]. How BDNF regulates integrins and adhesion complexes in the growth cone has remained incompletely defined [52-56]. Moreover, BDNF showed early promise as a central neural regenerative agent but, to date, no effective therapy has been developed that reliably stimulates functional recovery after a major human central nervous system event, such as a spinal cord injury [57-59]. Thus, elucidating the actions of BDNF on nerve growth and adhesion regulation in the combined presence of an inhibitory cue is of great interest.
Here, we report that BDNF induces the formation of nascent adhesion complexes in the growth cone that are necessary for the stimulation of axon growth by BDNF, as revealed by the sphingolipid L-t-lactosylceramide ( $\mathrm{L}$ $t$-LacCer), an inhibitor of lipid microdomain formation and integrin signaling, and through the use of a $\beta 1$ integrin specific function blocking antibody. Moreover, we tested the impact of BDNF and MAG in combination, discovering that BDNF-induced adhesions are protected from disruption by secondary MAG exposure, whereas non-clustered integrins remain susceptible to internalization. This finding provides mechanistic insight into a previous report that priming neurons with a neurotrophin before MAG exposure restored neurite lengths to near control levels [60]. In contrast, we found that prior exposure to MAG prevented BDNF-induced adhesion formation and abolished stimulated axon elongation. Taken together, this work lends support to the hypothesis that adhesion complexes are an important target for the development of effective neural regenerative therapies.

\section{Results \\ BDNF induces $\beta 1$-integrin clustering at the growth cone surface}

Based on previous findings that growth inhibitory factors negatively remodel growth cone adhesion complexes, we hypothesized that a neurotrophin can positively regulate the distribution of integrin receptors at the surface plasma membrane. Immunostaining unpermeablized Xenopus spinal neurons for surface $\beta 1$ integrin demonstrated a relatively homogeneous, diffuse localization at the growth cone with few focal clusters of enhanced fluorescence (Figure 1A). When neurons were treated with BDNF $(50 \mathrm{ng} / \mathrm{mL})$ for $5 \mathrm{~min}$, surface immunostaining revealed more numerous focal clusters of $\beta 1$-integrin in the growth cone periphery, which were often concentrated at filopodial tips (Figure 1A). Extending the duration of BDNF treatment to 20 min induced further $\beta 1$-integrin clustering, as determined by an increased number of focal $\beta 1$-integrin clusters. Quantitative analysis of thresholded images (see Methods) revealed a significant increase in the number of $\beta 1$ integrin clusters in the growth cone after BDNF treatment for 5 min (two-fold) and 20 min (three-fold) compared to vehicle treated controls (Figure 1B). Treatment with BDNF for 90 min induced $\beta 1$-integrin clustering comparable to the 20-min treatment (data not shown). We performed quality control analysis of the $\beta 1$-integrin clustering by randomly selecting 50 growth cones for reanalysis and testing a range of threshold values including two-, two and a half-, three- and four-fold above the background fluorescence (see Methods). Levels of $\beta 1$ - 


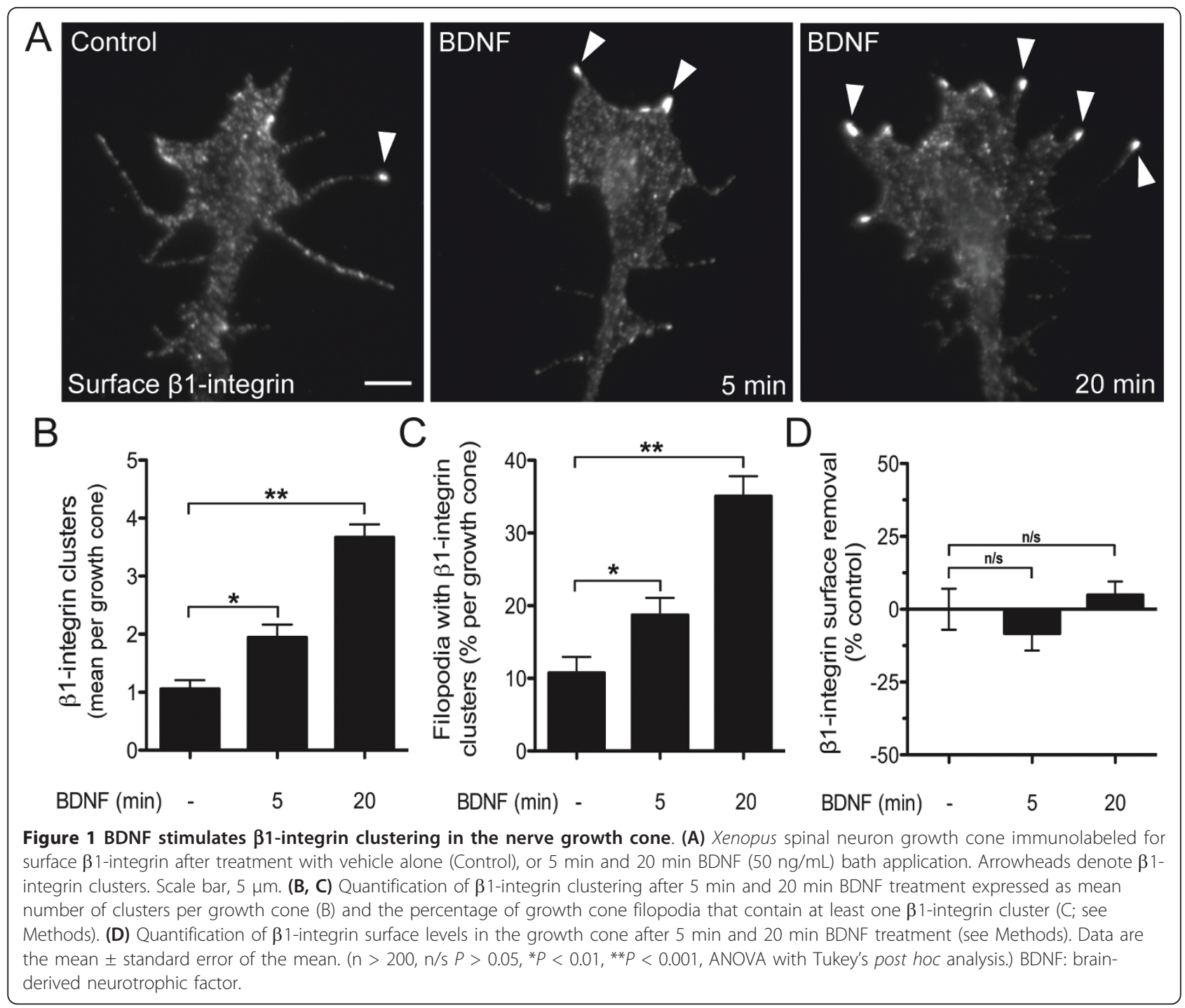

integrin clusters increased significantly after BDNF treatment at both $5 \mathrm{~min}$ and $20 \mathrm{~min}$ time points compared to controls for each of the threshold values tested, demonstrating the general robustness of the ordering to the threshold value (Additional file 1). The image thresholding at three times above background fluorescence likely underestimates the absolute number of focal clusters in the growth cone, as demonstrated by the quality control analysis, but enabled a useful and reproducible comparison of relative changes in $\beta 1$-integrin clustering between treatment groups. This quantitative approach also showed that the percentage of filopodia containing at least one $\beta 1$-integrin cluster increased after BDNF treatment (Figure 1C). In contrast, the overall surface levels of $\beta 1$-integrin in the growth cone remained unchanged after BDNF administration (Figure 1D). Thus BDNF induces integrin clustering rather than regulating global surface levels.

\section{BDNF induces formation of nascent adhesions}

To determine whether the $\beta 1$-integrin clustering induced by BDNF localized within adhesion complexes, we performed double immunolabeling for both $\beta 1$ integrin and known adhesion components. Treatment with BDNF induced $\beta 1$-integrin clustering that localized together with puncta of increased FAK fluorescence in the growth cone periphery (Figure 2A). A similar distribution of FAK has been reported previously in these spinal neuron growth cones, consistent with its known scaffolding and signaling functions at sites of substrate adhesions [43,61]. The BDNF-induced integrin clusters also labeled positive for phosphotyrosine (PY), vinculin and talin, which are enriched in adhesion complexes. In contrast, $\alpha$-actinin, a component of mature adhesions [62], was distinctly absent from the $\beta 1$-integrin clusters. Quantifying the percentage of $\beta 1$-integrin clusters that co-labeled for adhesion components revealed significant 


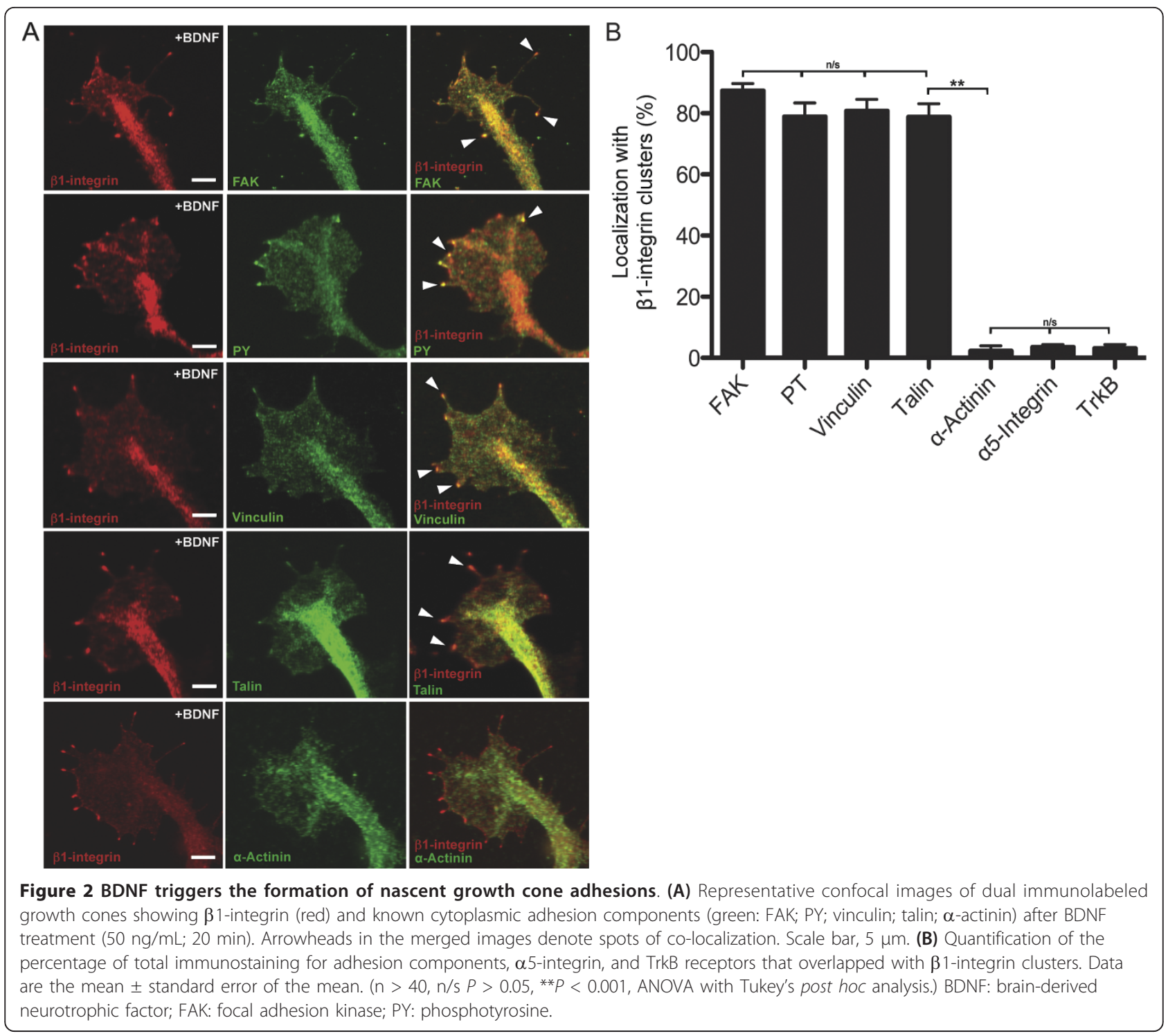

localization with FAK, phosphotyrosine, vinculin and talin but not $\alpha$-actinin (Figure 2B). The BDNF receptor Trk $B$ and $\alpha 5$-integrin were also absent from the $\beta 1$ integrin puncta (Figure 2B). Overall, this distribution pattern is consistent with selective BDNF-induced clustering of $\beta 1$-integrin within nascent adhesion complexes in the growth cone.

\section{Disrupting $\beta 1$-integrin function blocks BDNF-induced clustering}

Integrin clustering is known to occur within glycosphingolipid (GSL)-enriched microdomains. We tested whether the synthetic GSL L- $t$-LacCer, which effectively disrupts GSL microdomains and inhibits integrin activation and signaling at the cell surface [63], might prevent $\beta 1$-integrin clustering induced by BDNF. We first checked that cytoplasmic calcium ion $\left(\mathrm{Ca}^{2+}\right)$ signaling, which is triggered in these spinal neuron growth cones by BDNF [64], is unperturbed by L-t-LacCer pretreatment. Live-cell $\mathrm{Ca}^{2+}$ imaging revealed an elevation of cytoplasmic $\mathrm{Ca}^{2+}$, as detected by increased fluorescence $(>10 \%)$ of the $\mathrm{Ca}^{2+}$-sensitive indicator Fluo-8H, after BDNF treatment in four out of six growth cones imaged (Figure S2A in Additional file 2). In neurons pretreated with L- $t$-LacCer $(20 \mu \mathrm{M} ; 30 \mathrm{~min})$, BDNF induced a similar $\mathrm{Ca}^{2+}$ elevation in six out of eight growth cones imaged (Figure S2B in Additional file 2). Both the maximal fluorescence intensity increase during the recording period and the maximal mean fluorescence intensity increase within a $3-\mathrm{min}$ bin were similar in the BDNF alone and L- $t$-LacCer plus BDNF treatment groups (Figure S2C, D in Additional file 2). Thus, $\mathrm{Ca}^{2+}$ signals 


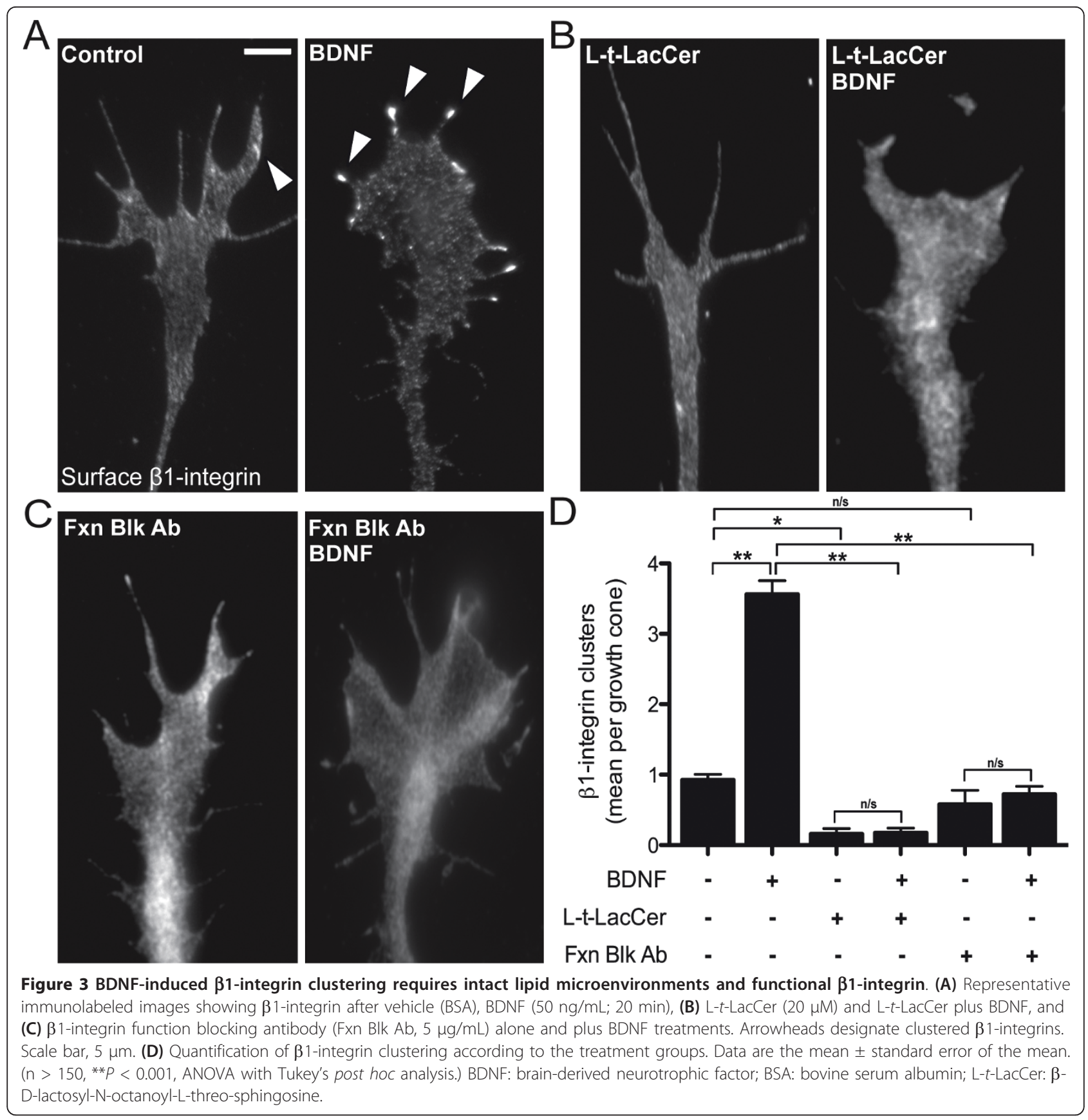

downstream of BDNF treatment appear relatively normal in the growth cone after L-t-LacCer pretreatment. In contrast, pretreatment with L- $t$-LacCer reduced the surface $\beta 1$-integrin clustering in the growth cone compared with vehicle treated controls and prevented clustering after a subsequent BDNF treatment $(20 \mathrm{~min}$; Figure 3A, B, D). The global surface levels of both $\beta 1$ integrin and TrkB remained unchanged after treatment with L-t-LacCer compared to vehicle treated controls (Additional files 3 and 4).
We further addressed whether integrin function was necessary for $\beta 1$-integrin clustering by utilizing the specific $\beta 1$-integrin function-blocking antibody 2999 [65]. Pretreatment with antibody $2999(5 \mu \mathrm{g} / \mathrm{mL} ; 20 \mathrm{~min})$ reduced the surface $\beta 1$-integrin clustering in the growth cone compared to vehicle treated controls and prevented BDNF-stimulated $\beta 1$-integrin clustering (Figure $3 \mathrm{~A}, \mathrm{C}, \mathrm{D})$. Total surface levels of both $\beta 1$-integrin and TrkB were unchanged after treatment with antibody 2999 compared to vehicle treated controls (Additional 
files 3 and 4). Taken together, these findings support the notion that disrupting $\beta 1$-integrin function blocks BDNF-dependent integrin clustering.

Is integrin clustering necessary for neurotrophin stimulation of neurite outgrowth? We addressed this by performing functional live-cell growth assays. Acute treatment with BDNF stimulated axon elongation during the 60-min assay as compared to vehicle treated controls (Figure 4A, B). Pretreatment with L-t-LacCer to disrupt integrin clustering before the growth assay reduced axon elongation compared with vehicle treated controls and impaired the BDNF-induced stimulation of outgrowth (Figure 4A, B). In contrast, pretreatment with the natural stereoisomer D-lactosyl- $\beta 1-1$ '-N-octanoyl-Derythro-sphingosine (D-e-LacCer) permitted both normal basal outgrowth and the stimulation of outgrowth after a subsequent BDNF treatment (Figure 4B). Pretreatment with $\beta 1$-integrin function-blocking antibody 2999 to prevent integrin clustering also impaired BDNF-stimulated axon elongation, whereas pretreatment with a control antibody permitted normal BDNF-dependent axon extension (Figure 4B). Altogether, these findings suggest that integrin clustering and activation are necessary for the stimulation of axon outgrowth by a neurotrophin.

We next tested whether treatment with either L- $t$-LacCer or the function-blocking antibody might impair growth cone membrane expansion, a stereotyped functional response to BDNF administration [66]. Molecular expression of a GFP-tagged chimera of paxillin, a cytoplasmic component of growth cone adhesions [67], demonstrated significant membrane expansion after BDNF treatment, as visualized by total internal reflection fluorescence (TIRF) microscopy to permit imaging exclusively at the ventral membrane contacting the substrate (Additional file 5). We also noted the rapid formation of numerous GFP-paxillin puncta consistent with nascent adhesions after BDNF treatment (Additional file 5). Measurements of growth cone diameter (see Methods) demonstrated that BDNF treatment caused significant widening of the growth cone compared with the pretreatment diameter (Figure S5A, B in Additional file 6). Significantly, neither the L-t-LacCer pretreatment nor the function-blocking antibody 2999 impaired the BDNF-induced growth cone expansion (Figure S5A, B in Additional file 6). Thus, both L-t-LacCer and the function-blocking antibody 2999 block BDNF-induced $\beta 1$-integrin clustering and stimulation of axon outgrowth without disrupting BDNF signaling and downstream membrane expansion.

\section{BDNF-induced $\beta 1$-integrin clustering is $\mathrm{Ca}^{2+}$-dependent} Cytoplasmic $\mathrm{Ca}^{2+}$ is an important second messenger for axon guidance signaling and is essential for positive growth cone chemotaxis towards a point source of

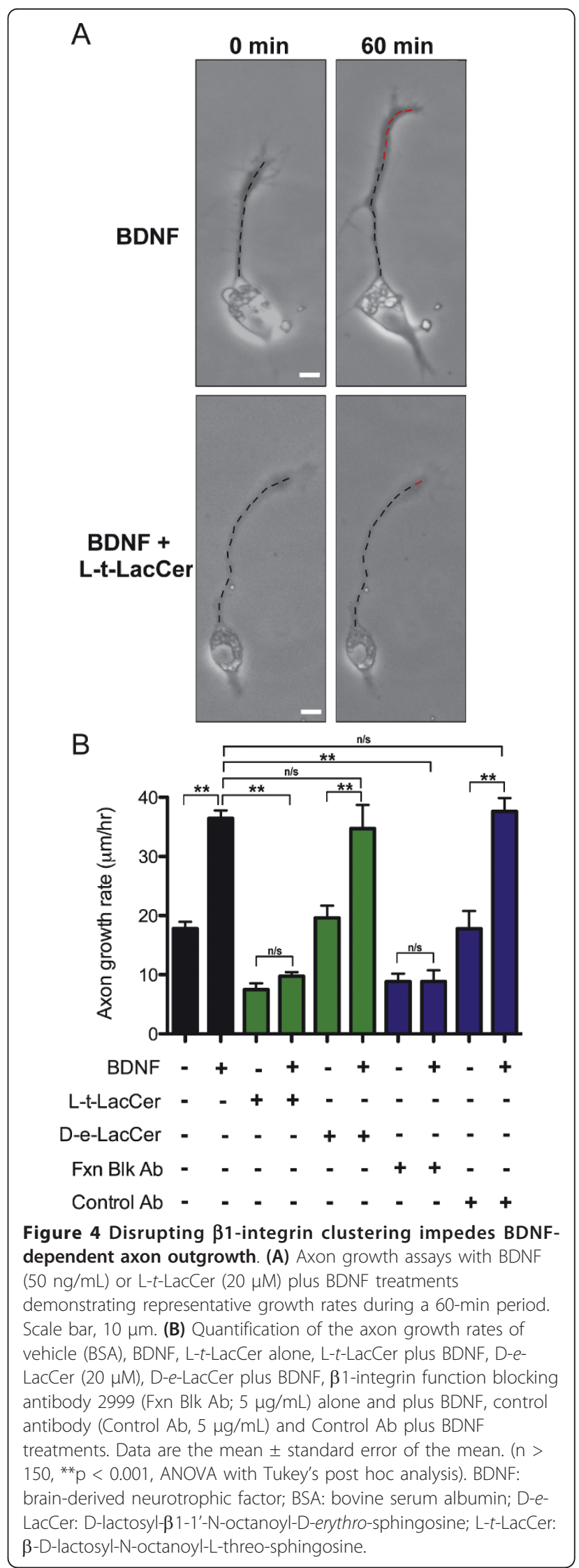


BDNF in these spinal neurons $[9,68]$. To determine the role of $\mathrm{Ca}^{2+}$ signaling during $\beta 1$-integrin clustering by BDNF, we utilized the cell-permeant chelator BAPTA$\mathrm{AM}$, which effectively buffers cytoplasmic $\mathrm{Ca}^{2+}$. Surface immunolabeling revealed that pretreatment with BAPTA-AM completely blocked $\beta 1$-integrin clustering induced by BDNF (Figure 5A, B). Pretreatment with 50 $\mu \mathrm{M}$ cadmium chloride $\left(\mathrm{CdCl}_{2}\right)$ to nonselectively block voltage-dependent plasmalemmal $\mathrm{Ca}^{2+}$ channels $[69,70]$ also abolished the $\beta 1$-integrin clustering induced by BDNF (Figure 5B). When spinal neurons were pretreated with BAPTA-AM during functional live-cell growth assays, the rate of constitutive axon elongation was reduced compared with normal $\mathrm{Ca}^{2+}$ controls (Figure 5C). Importantly, BAPTA-AM treatment completely abolished the BDNF-stimulated growth rate compared

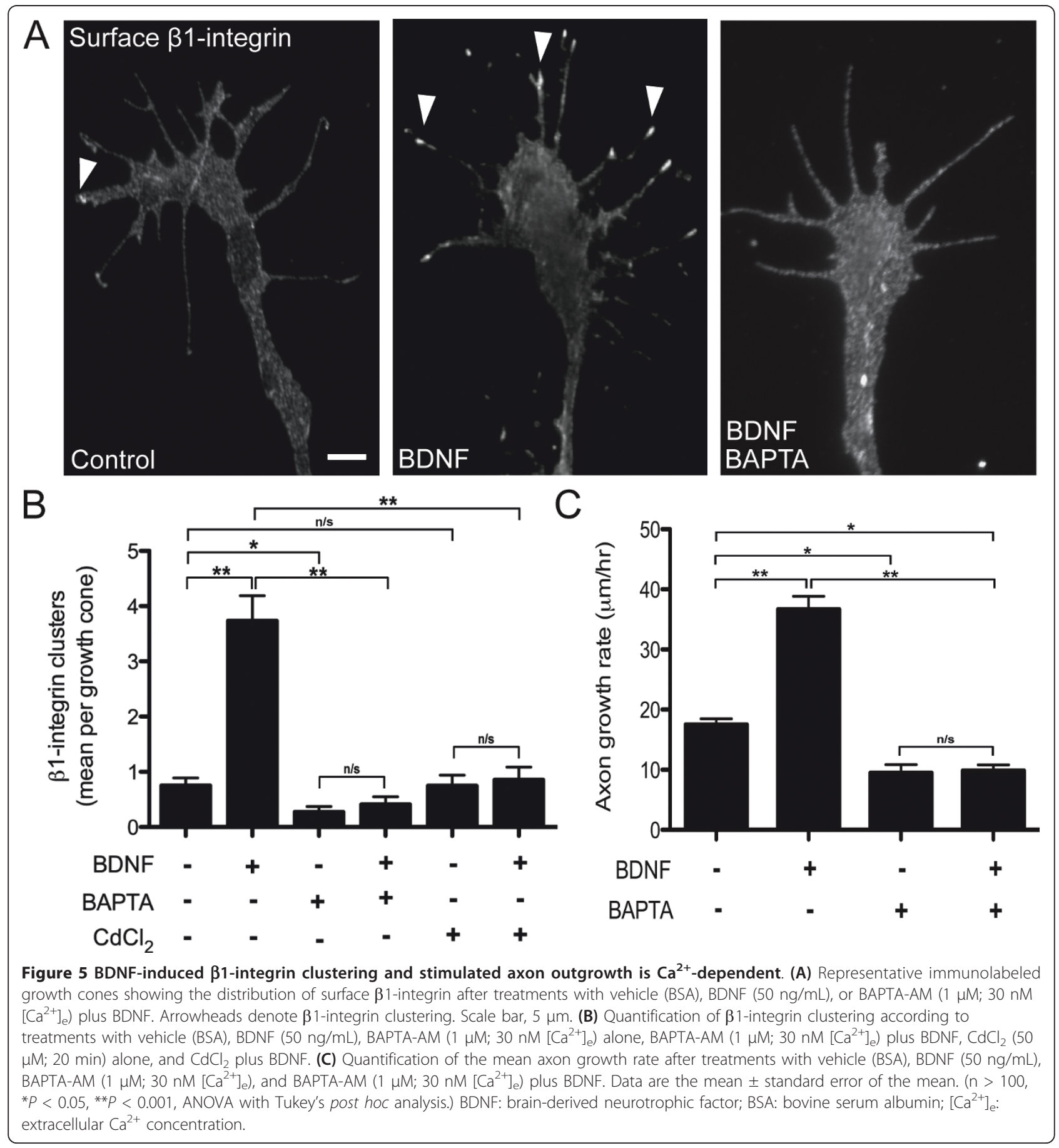


to normal $\mathrm{Ca}^{2+}$ controls. Taken together, these findings demonstrate that both $\beta 1$-integrin clustering and stimulation of axon outgrowth by BDNF require intracellular $\mathrm{Ca}^{2+}$ signaling.

\section{BDNF-induced $\beta 1$-integrin adhesions resist downregulation by MAG}

We next tested whether the positive regulation of $\beta 1$ integrin adhesions by BDNF might counteract negative remodeling by MAG. In growth cones exposed to MAG $(1 \mu \mathrm{g} / \mathrm{mL})$, surface immunostaining and quantitative analysis after image thresholding revealed a complete loss of clustered $\beta 1$-integrin compared to vehicle treated controls (Figures 6A, B and 7). In contrast, pretreatment with BDNF (50 $\mathrm{ng} / \mathrm{mL}$ ) induced the formation of $\beta 1$ integrin clusters that persisted even after a subsequent MAG exposure (Figures 6A, B and 7). We next asked whether BDNF might induce integrin clustering in the presence of MAG. In growth cones first exposed to MAG followed by a subsequent BDNF treatment, the $\beta 1$-integrin clustering was abolished unlike the vehicle treated controls (Figures 6A, B and 7). Thus, BDNF priming induces $\beta 1$-integrin clustering that can resist negative remodeling by MAG exposure, but secondary BDNF treatment cannot overcome the MAG-induced loss of clustering. Quality control analysis of the $\beta 1$ integrin clustering using a range of threshold values including two-, two and a half-, three- and four-fold above the background fluorescence (see Methods), demonstrated statistical reliability for every data set except two experimental conditions that were analyzed with a threshold value four-fold above background fluorescence (Additional file 7).

Quantifying the mean surface $\beta 1$-integrin immunostaining showed a reduction in global surface levels after MAG exposure alone compared with vehicle treated controls (Figures $6 \mathrm{C}$ and 7). Pretreatment with BDNF followed by MAG exposure partially protected the global surface levels of $\beta 1$-integrin, which were elevated compared with MAG exposure alone, but were reduced compared with BDNF treatment alone (Figures $6 \mathrm{C}$ and 7). In growth cones first exposed to MAG followed by a subsequent BDNF treatment, the global surface levels of $\beta 1$-integrin were reduced by levels comparable to those after MAG exposure alone (Figure 6C and 7). Altogether, these results suggest that the initial exposure to a positive or negative chemotropic cue may determine the level of $\beta 1$-integrin clustering in the growth cone. Moreover, the mechanisms regulating integrin clustering can be distinct from those controlling the global level at the growth cone surface membrane.

Does the level of integrin clustering regulate axon extension? Pretreating rat cerebellar and dorsal root ganglion neurons with BDNF before plating onto MAG- expressing cells has been shown to block the growth inhibitory effects of chronic exposure to MAG in a 24hour growth assay [60]. We tested for a correlation between the rate of axon extension and the direction of adhesion remodeling in the growth cone during acute exposure to MAG and BDNF. Treatment with BDNF stimulated the rate of axon extension during the 60-min functional assay, whereas single exposure to MAG-alone inhibited outgrowth compared to vehicle treated controls (Figures 6D and 7). In dual exposure assays, pretreatment with BDNF followed by MAG application resulted in a restoration of control levels of axon growth (Figures 6D and 7). On the other hand, initial MAG exposure followed by BDNF led to a relatively modest improvement in outgrowth over MAG treatment alone and was significantly reduced compared to control levels (Figures 6D and 7). Thus, the MAG-induced inhibition of axon extension correlates with negative $\beta 1$-integrin clustering and reduced surface levels, and restoration of basal growth rate correlates with positive $\beta 1$-integrin clustering and maintained surface levels. Stimulated outgrowth by BDNF may require both $\beta 1$-integrin clustering and the complete protection of normal surface levels.

\section{Discussion}

\section{Positive regulation of growth cone adhesions by BDNF}

In a previous report, we demonstrated that a soluble form of MAG directs $\beta 1$-integrin internalization to negatively modulate the functional distribution of integrin adhesions in the growth cone during repulsive guidance. Here, we have expanded on these findings by revealing that the neurotrophin BDNF positively regulates the formation of nascent integrin adhesions in the growth cone. The BDNF-induced clustering of $\beta 1$-integrin localized to sites of substrate adhesions that colabeled with bona fide adhesion components, including FAK, vinculin, phosphotyrosine and talin. The $\beta 1$-integrin clustering was rapid, occurring during a 5 -min BDNF treatment. Interestingly, the newly formed adhesions were negative for $\alpha$-actinin, a component of more mature stable adhesion complexes, even after a 20 -min BDNF treatment. These results are consistent with the notion that BDNF may stimulate both the formation and turnover of nascent adhesions, since stabile adhesions persisting for longer than $15 \mathrm{~min}$ would be expected to recruit $\alpha$-actinin. Our finding, that $\beta 1$-integrin clustering reached a new steady state during a 20min BDNF treatment without any further increase after a 90-min treatment, further supports this idea. However, an alternative interpretation is that BDNF induces the formation of a distinct subclass of integrin adhesions in the growth cone that are $\alpha$-actinin negative. While this manuscript was in review, a complementary finding was 


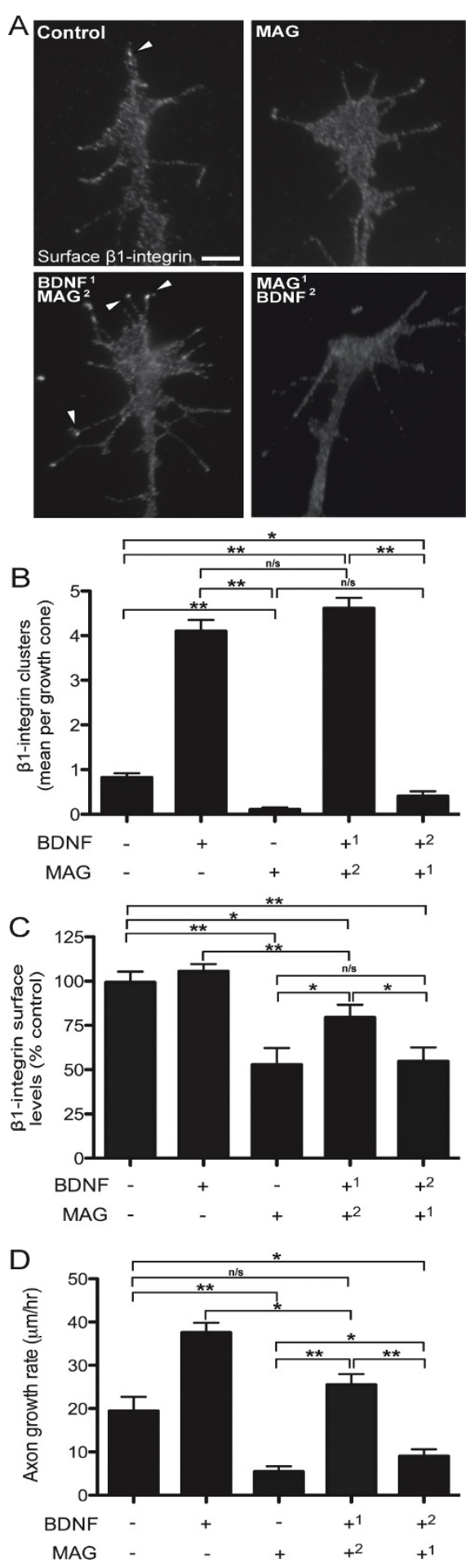

Figure 6 BDNF priming counteracts inhibitory MAG-effects on $\beta 1$-integrin clustering and growth inhibition. (A) Representative immunolabeled images showing $\beta$ 1-integrin after control (BSA), MAG $(1 \mu \mathrm{g} / \mathrm{mL} ; 5 \mathrm{~min})$, or combination treatments with BDNF $(50 \mathrm{ng} / \mathrm{mL} ; 20$ $\mathrm{min}$ ) and MAG. Detailed time course graphical representation of the combination treatments located in Additional file 8 . Arrowheads designate clustered $\beta$ 1-integrins. Scale bar, $5 \mu \mathrm{m}$. (B) Quantification of $\beta$ 1-integrin clustering after vehicle (BSA), BDNF (50 $\mathrm{ng} / \mathrm{mL})$, and $\mathrm{MAG}(1 \mu \mathrm{g} / \mathrm{mL})$ treatments alone or followed by secondary exposure to BDNF or MAG. (C) Quantification of $\beta 1$-integrin surface levels after vehicle (BSA), BDNF $(50 \mathrm{ng} / \mathrm{mL})$, and MAG $(1 \mathrm{\mu g} / \mathrm{mL})$ treatments alone or followed by secondary exposure to BDNF or MAG. (D) Quantification of the mean axon growth rate according to the treatment groups. Data are the mean \pm standard error of the mean. $\left(n>150,{ }^{*} P<0.01\right.$, **P $<0.001$, ANOVA with Tukey's post hoc analysis.) BDNF: brain-derived neurotrophic factor; BSA: bovine serum albumin; MAG: myelin-associated glycoprotein. 


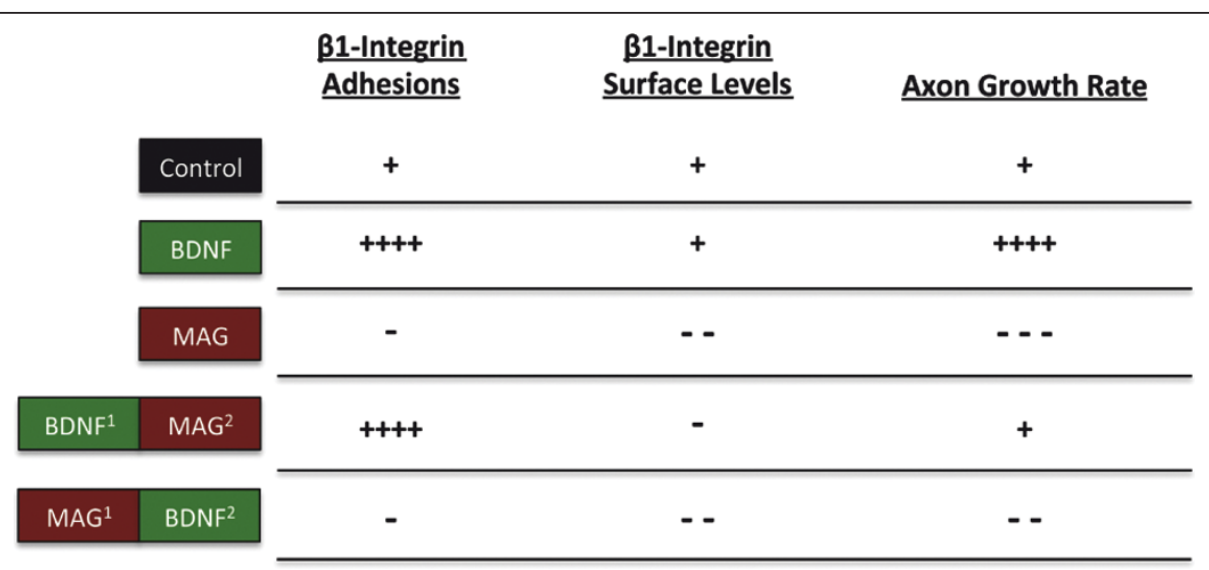

Figure $\mathbf{7}$ Comparison of bidirectional $\boldsymbol{\beta} 1$-integrin remodeling during nerve growth. Summary figure showing the clustering and global surface levels of $\beta 1$-integrin in the growth cone correlated with the mean axon growth rate for the experimental treatments in Figure 6. Superscripts denote order of treatment. Symbols (+/-) denote positive and negative effects relative to controls.

reported, that BDNF stimulates FAK-dependent formation and turnover of paxillin-containing substrate point contacts in the axonal growth cone during chemoattractive guidance [71]. This provided independent validation that BDNF induces nascent adhesions.

The BDNF-induced clustering of $\beta 1$-integrin and stimulation of axon growth both required elevation of cytoplasmic $\mathrm{Ca}^{2+}$, a key second messenger downstream of TrkB activation, and functional lipid microdomains in the surface plasma membrane. How might local $\mathrm{Ca}^{2+}$ signals facilitate integrin clustering and adhesion formation? It is well established that a rise in cytoplasmic $\mathrm{Ca}^{2}$ $+\left(\left[\mathrm{Ca}^{2+}\right]_{\mathrm{i}}\right)$ leads to $\mathrm{Ca}^{2+} /$ calmodulin-dependent protein kinases II (CamKII) activation [72,73]. One possibility is that CamKII activity positively regulates Tiam1 [74,75], Ras-GRF1/2 [76] and other guanine exchange factors to mediate Rho-family guanosine triphosphatase-dependent cytoskeletal dynamics and adhesion assembly [67,77]. An increase in $\left[\mathrm{Ca}^{2+}\right]_{\mathrm{i}}$ has also been shown to trigger protein kinase $\mathrm{C}$-mediated phosphorylation of Rho-guanosine nucleotide dissociation inhibitor, which then stimulates Rac localization to the plasma membrane [78]. Alternatively, $\left[\mathrm{Ca}^{2+}\right]_{\mathrm{i}}$ elevation may initiate synaptotagmin I-mediated vesicular trafficking of adhesion receptors and components to focal sites at the plasma membrane, leading to increased adhesion formation and outgrowth [79]. Elucidating the signaling cascade initiated by BDNF that mediates integrin-based adhesion formation will be an important area of future investigation.

Many groups have now reported that the non-arbitrary, asymmetrically distributed lipids, including cholesterol and sphingolipids, influence integrin adhesion and signaling functions $[36,80]$. Specifically, the glycosphingolipid GM3 has been shown to directly regulate integrin-substrate interactions [81]. Additionally, talin and vinculin contain lipid binding sites that are thought to regulate adhesion formation and turnover [82]. Previous reports demonstrated that the synthetic GSL L-tLacCer incorporates into the surface plasma membrane, disrupting lipid microdomains, integrin clustering and subsequent integrin activation [63]. Our finding, that L$t$-LacCer disrupted $\beta 1$-integrin clustering in the growth cone and attenuated the basal rate of axon outgrowth, is consistent with an essential role for the lipid microenvironment in normal integrin adhesion and signaling functions. This effect was more pronounced in the presence of BDNF, when L- $t$-LacCer pretreatment completely blocked $\beta 1$-integrin clustering and prevented stimulation of axon extension. Our complementary results with the function-blocking antibody provide further support for the notion that BDNF-induced clustering of $\beta 1$-integrin is essential for stimulated axon outgrowth. Altogether, our findings support a model whereby $\mathrm{Ca}^{2+}$-dependent signaling downstream of BDNF binding and TrkB activation induces the rapid clustering and formation of nascent $\beta 1$-integrin adhesions in the growth cone to stimulate axon growth rate. Such dynamic remodeling may allow the growth cone to rapidly adjust adhesiveness to the extracellular matrix, providing a general mechanism for governing axon extension.

\section{Chemotropic effects determined by diametric regulation of growth cone adhesions}

We showed previously that a diffusible microscopic gradient of MAG remodels growth cone adhesions asymmetrically during repulsive chemotactic guidance. Here, we have shown that the rapid global downregulation of functional $\beta 1$-integrin adhesions at the growth cone 
surface membrane, induced by uniform exposure to MAG, correlates with the inhibition of axon extension in a similar time frame. The mechanism is $\mathrm{Ca}^{2+}$-dependent but distinct from the action of BDNF, since MAG triggers removal of $\beta 1$-integrin from the surface membrane whereas total surface levels of $\beta 1$-integrin remain unchanged by BDNF treatment. Thus, BDNF and MAG remodel growth cone adhesions in opposite directions during stimulation and inhibition of axon outgrowth, respectively. Importantly, the microenvironment of growth cone adhesions induced by BDNF protected against MAG-disruption and $\beta 1$-integrin internalization. This BDNF priming did not block MAG-induced internalization of non-clustered $\beta 1$-integrin, suggesting that the priming effect occurred by a mechanism other than cross-desensitization of receptors or second messengers. Internalization of the non-clustered integrin pool may partially account for the failure of BDNF priming to maximally stimulate nerve growth when MAG is present.

Treatment with BDNF after MAG application precludes adhesion formation and may provide a partial explanation for the relative lack of efficacy BDNF showed in human spinal cord regenerative efforts. We found that secondary BDNF treatment after MAG preexposure caused only a relatively modest improvement in the growth rate compared with MAG exposure alone, and was significantly attenuated compared with the control unperturbed growth rate. Neurotrophins can stimulate many cellular processes that are key for axon outgrowth. These include sprouting of new filopodia and membrane expansion at the growth cone, regulating actin dynamics and microtubule elongation, in addition to the formation of nascent substrate adhesions. Exposure to MAG may suppress many, but not necessarily all, of these actions. Taken together, our findings provide additional rationale for future studies aimed at manipulating the regulation of adhesion complexes in a translational regenerative model. We speculate that manipulations to disrupt the cycle of $\beta 1$-integrin surface removal by MAG, such as inhibiting clathrin-mediated endocytosis or stimulating integrin activation and receptor redistribution, may potentially allow nerve growth stimulating agents like BDNF to positively regulate growth cone adhesions and encourage outgrowth through an inhibitory environment.

\section{Conclusions}

This study demonstrates that the neurotrophin-induced formation of integrin-based adhesions in the growth cone, which is $\mathrm{Ca}^{2+}$-dependent, requires the clustering and activation of $\beta 1$-integrin, and correlates with the stimulation of axon growth rate. This positive remodeling of integrin adhesions by BDNF opposes the negative remodeling induced by MAG during the inhibition of axon extension. Moreover, the BDNF-induced integrin clustering is resistant to negative remodeling by MAG, revealing a potential mechanism to explain how BDNF can block the growth inhibitory effects of MAG. Future therapeutic strategies targeted to manipulate dynamic integrin remodeling and activation state may be important for overcoming local inhibitory factors after traumatic injury or neurodegenerative disease to enhance neural regeneration.

\section{Methods}

\section{Ethics statement}

All animal experiments were carried out with strict adherence to National Institutes of Health (NIH) Guidelines for animal care and safety and were approved by the Mayo Clinic Institutional Animal Care and Use Committee.

\section{Primary cell culture of Xenopus spinal neurons}

Wild-type Xenopus laevis (Xenopus One) were maintained in approved animal facilities according to institutional guidelines. Experiments were conducted on spinal neurons prepared from neural tube dissections of oneday old (stage 22) X. laevis embryos [83]. These cultures are used for experiments $10 \mathrm{~h}$ to $14 \mathrm{~h}$ after plating on fibronectin substrate at $20^{\circ} \mathrm{C}$ to $22^{\circ} \mathrm{C}$. All cover glasses were coated with poly-D-lysine $(5 \mathrm{mg} / \mathrm{mL}$, Sigma, St. Louis, MO, USA) followed by fibronectin $(20 \mu \mathrm{g} / \mathrm{mL}$, Sigma). Culture medium consisted of $87.5 \%$ (v/v) Leibovitz medium (GIBCO, Grand Island, NY, USA) containing $0.4 \%(\mathrm{v} / \mathrm{v})$ fetal bovine serum (HyClone, Logan, UT, USA), and $12.5 \%(\mathrm{v} / \mathrm{v})$ saline solution (10 mM D-glucose, 5 sodium pyruvate, $1.26 \mathrm{mM}$ calcium chloride $\left(\mathrm{CaCl}_{2}\right)$ and $32 \mathrm{mM}$ HEPES; $\mathrm{pH}$ 7.5). Experiments were performed in modified Ringers solution (120 mM sodium chloride $(\mathrm{NaCl}), 2.2 \mathrm{mM}$ potassium chloride (KCl), $2 \mathrm{mM} \mathrm{CaCl}, 1 \mathrm{mM}$ magnesium chloride $\left(\mathrm{MgCl}_{2}\right)$, $5 \mathrm{mM}$ HEPES, $2 \mathrm{mM}$ sodium pyruvate; $\mathrm{pH}$ 7.6). All animal research was performed with the approval of Mayo Clinic Institutional Animal Care and Use Committee.

\section{Reagents, immunolabeling and microscopy}

Spinal neuron cultures were treated with MAG-Fc (1 $\mu \mathrm{g} / \mathrm{mL}, \mathrm{R} \& D$ Systems \#538-M, Minneapolis, MN, USA; conjugated to Fc-specific goat anti-human immunoglobulin G, Jackson IR Labs 109-485-098, West Grove, PA, USA), BDNF (50 ng/mL, Peprotech \#450-02, Rocky Hill, NJ, USA), both or a control BSA vehicle solution for predetermined times, followed by standard chemical fixation. MAG treatments for $5 \mathrm{~min}$ were utilized to obtain maximal integrin surface removal [16]. Spinal neuron cultures were chemically fixed in a cytoskeleton- 
stabilizing buffer containing 2.5\% paraformaldehyde and $0.01 \%$ glutaraldehyde for $20 \mathrm{~min}$. All blocking and immunolabeling steps were performed in modified Ringers solution containing $5 \%$ goat serum. Alexa-dyelabeled secondary antibody conjugates (Invitrogen, Carlsbad, CA, USA) were used at $2 \mu \mathrm{g} / \mathrm{mL}$. We immunolabeled unpermeabilized cells using a monoclonal antibody to the extracellular domain of $\beta_{1}$-integrin (8c8c, $0.8 \mu \mathrm{g} / \mathrm{mL}$, University of Iowa Developmental Studies Hybridoma Bank) or with a $\beta_{1}$-integrin function-blocking antibody (2999, $0.4 \mu \mathrm{g} / \mathrm{mL}$, K. Yamada) along with a polyclonal anti- $\beta$-tubulin antibody $(0.4 \mu \mathrm{g} / \mathrm{mL}$, Abcam ab15568, Cambridge, England). Antibody staining for vinculin $(2 \mu \mathrm{g} / \mathrm{mL}$, Sigma V931), FAK $(2 \mu \mathrm{g} / \mathrm{mL}$, Santa Cruz Biotechnology sc-557, Santa Cruz, CA, USA), phosphotyrosine p-Tyr PY99 $(1 \mu \mathrm{g} / \mathrm{mL}$, Santa Cruz BioTechnology sc-7020), $\alpha 5$-integrin $(1 \mu \mathrm{g} / \mathrm{mL}, \mathrm{D}$. DeSimone), TrkB (4 $\mu \mathrm{g} / \mathrm{mL}$, Novus NB100-92063, Littleton, CO, USA), $\alpha$-actinin $(1 \mu \mathrm{g} / \mathrm{mL}$, Santa Cruz Biotechnology sc-59953) and talin $(0.8 \mu \mathrm{g} / \mathrm{mL}, \mathrm{Abcam}$ ab1188) was performed on permeabilized cells $(0.1 \%$ Triton-X-100), followed by Alexa555 secondary antibody conjugates. Fluorescence microscopy was performed using a Zeiss (Jena, Germany) LSM 5LIVE confocal microscope equipped with a $63 \times$ oil immersion objective (1.4 numerical aperture, $1.6 \times$ optical zoom) with identical acquisition settings for control and experimental groups. The paxillin-GFP construct was provided by T.M. Gomez (University of Wisconsin, Madison). GFP-paxillin RNA was injected into four-celled Xenopus embryos. Spinal neurons were plated onto laminin $(80 \mu \mathrm{g} / \mathrm{mL})$ and incubated for $3 \mathrm{~h}$ to $4 \mathrm{~h}$ at $23^{\circ} \mathrm{C}$ to $25^{\circ} \mathrm{C}$ before use. High-magnification images were acquired using a Zeiss AxioCam MRm and $100 \times / 1.45$ NA objective on a Zeiss TIRF microscope.

\section{Image analysis and processing}

To measure only receptors at the plasma membrane, permeabilized growth cones were excluded inadvertently from the analysis, as identified by tubulin immunofluorescence with polyclonal anti- $\beta$-tubulin. The original 14bit images were analyzed using ImageJ (Bio-Formats ZVI plug-in, Madison, WI, USA). A region of interest encompassing the entire growth cone (defined as the distal $20 \mu \mathrm{m}$ ) was used to determine the mean fluorescence intensity of thresholded images (identical for experimental and control conditions). Data were background subtracted and normalized to the appropriate control images. Growth cones with a mean $\beta 1$-integrin fluorescence level less than double the background fluorescence were excluded from analysis. For quantification of integrin clustering, we used a three-fold fluorescence inclusion criterion of $\beta 1$-integrin cluster intensity over the mean background fluorescence in the growth cone central domain. Only clusters within the distal $20 \mu \mathrm{m}$ of the axon and within $5 \mu \mathrm{m}$ of the lateral borders of the growth cone (growth cone peripheral domain) were included. Quantification of $\beta 1$-integrin clustering for quality control analysis was performed by randomly selecting growth cones $(n=50)$ for reevaluation with a range of fluorescence threshold values (two-, two and a half-, three-, and four-fold above the background fluorescence) [84]. To quantify co-labeling with $\beta 1$-integrin puncta, a two-fold fluorescence increase relative to the mean fluorescence in the growth cone central domain was utilized for identifying cytoplasmic protein clusters. The growth cone diameter was determined using ImageJ by measuring from the lateral edges of lamellipodia at the widest point of the growth cone, excluding filopodia. The GFP-paxillin TIRF microscopy movie was made using ImageJ software by exporting time-lapse stacks to a QuickTime format (MOV, MPEG4 compression, 3 frames per second).

\section{Manipulation of $\beta 1$-integrin clustering}

We disrupted BDNF-induced integrin clustering using a 30 -min pretreatment with the glycosphingolipid L- $t$-LacCer: $\beta$-D-lactosyl-N-octanoyl-L-threo-sphingosine (20 $\mu \mathrm{M}$, Avanti Polar Lipids, Alabaster, AL, USA). The natural stereoisomer D-e-LacCer: D-lactosyl- $\beta 1-1$ '-N-octanoyl-D-erythro-sphingosine $(20 \mu \mathrm{M}$, Avanti Polar Lipids) was used as a control lipid. Both L-t-LacCer and D-e-LacCer were complexed to defatted BSA and incubated with cells at a final concentration of $20 \mu \mathrm{M}$ [63]. Integrin function was inhibited by a 20-min pretreatment with the function-blocking antibody $2999(5 \mu \mathrm{g} /$ $\mathrm{mL})$. To buffer intracellular $\mathrm{Ca}^{2+}$, neuron cultures were incubated for $30 \mathrm{~min}$ in low- $\mathrm{Ca}^{2+}(30 \mathrm{nM})$ solution consisting of $50 \%$ culture medium and $50 \%$ ethylene glycol tetraacetic acid (EGTA)-buffered saline (120 NaCl mM, $4.9 \mathrm{KCl} \mathrm{mM,} 1.55 \mathrm{mM} \mathrm{MgCl}$, $1.25 \mathrm{mM}$ glucose, $5 \mathrm{mM}$ sodium pyruvate, $4 \mathrm{mM}$ HEPES, $0.65 \mathrm{mM}$ EGTA, pH 7.6) and BAPTA-AM (1,2-bis-(o-aminophenoxy)-ethane$\mathrm{N}, \mathrm{N}, \mathrm{N}$ ', N'-tetraacetic acid, tetraacetoxymethyl ester, 1 $\mu \mathrm{M}$; Calbiochem, Gibbstown, NJ, USA) or dimethyl sulfoxide vehicle for $30 \mathrm{~min}$, followed by consecutive washes in low- $\mathrm{Ca}^{2+}$ saline. To broadly disrupt $\mathrm{Ca}^{2+}$ influx via voltage-dependent $\mathrm{Ca}^{2+}$ channels in the plasmalemma, neurons were pretreated for $20 \mathrm{~min}$ with $\mathrm{CdCl}_{2}(50 \mu \mathrm{M}$, Sigma) as reported previously [70].

\section{Live-cell $\mathrm{Ca}^{2+}$ imaging}

$X$. laevis spinal neurons were loaded with the fluorescence $\mathrm{Ca}^{2+}$ sensor Fluo-8H $(2 \mu \mathrm{M}, 30$-min loading in culture medium containing $0.01 \%$ pluronic acid, AAT Bioquest, Sunnyvale, CA, USA). Growth cones were subjected to $\mathrm{Ca}^{2+}$ imaging within 45 min of dye loading, using a Zeiss $200 \mathrm{M}$ inverted microscope equipped with 
a 100X/1.45 NA objective and EM-CCD camera (Hamamatsu, Bridgewater, NJ, USA). Image acquisition was every $15 \mathrm{~s}$ and was started at least $2 \mathrm{~min}$ prior to application of BDNF (50 ng/mL). To measure fluorescence intensity, each series of images was thresholded to eliminate background noise, and the mean fluorescence intensity within a region of interest drawn around the growth cone was measured using ImageJ software (NIH). For each growth cone, the mean fluorescence intensity of each image after BDNF treatment $(F)$ was then compared to the mean baseline fluorescence (preBDNF treatment; $F_{0}$ ) to obtain the displayed value of normalized fluorescence $\left(\mathrm{F} / \mathrm{F}_{0}\right)$.

\section{Functional axon outgrowth assay}

For measurements of neurite outgrowth in response to the various treatment groups, a series of time-lapse images were taken to record growth over a 60-min period (ProgRes CapturePro 2.7, Jenoptik Inc., Jupiter, FL, USA). Neurons were pretreated with L-t-LacCer or D-eLacCer for $30 \mathrm{~min}$ in appropriate assays. A 20 -min pretreatment was used for outgrowth assays with the function blocking antibody 2999 and a control antibody. All outgrowth assays were performed on a Zeiss 40 compact fluorescent lamp microscope equipped with a Ludl Electronic Products (Hawthorne, NY, USA) BioPoint 2 motorized stage, cooled charged-coupled device camera and a $20 \times$ objective. Only axons $>50 \mu \mathrm{m}$ in length were included in the analysis. Analysis was conducted using ImageJ.

\section{Statistical analyses}

All statistical analyses were performed using GraphPad Prism software (v5, La Jolla, CA, USA). The figure legends state the statistical tests used. Data with a normal distribution (D'Agostino and Pearson omnibus normality test) were assessed using repeated-measures oneway analysis of variance with a Tukey post hoc analysis.

\section{Additional material}

Additional file 1: Figure S1-Quality control analysis of $\beta 1$-integrin clustering after time course BDNF treatments. Growth cones from each experimental group in Figure 1B were randomly selected for quantification of $\beta 1$-integrin clustering reanalysis (Research Randomizer $\mathrm{V}$. 3.0 software), using a range of fluorescence threshold values (two-, two and a half-, three- and four-fold above the background fluorescence). Data are the mean \pm s.e.m. ( $n=50,{ }^{*} P<0.05$ as compared to control, ANOVA with Tukey's post hoc analysis.)

Additional file 2: Figure S2-BDNF-induced $\mathrm{Ca}^{2+}$ signals after L-tLacCer pretreatment. (A) Representative images of the Fluo- $8 \mathrm{H} \mathrm{Ca}^{2+}$ sensor in the growth cone before (left) and after (right) BDNF $(50 \mu \mathrm{g} / \mathrm{mL})$ treatment. Pseudocolor scale, blue $=$ lower $\mathrm{Ca}^{2+}$ and white $=$ higher $\mathrm{Ca}^{2+}$ concentrations. Scale bar, $5 \mu \mathrm{m}$. (B) As in (A) but with L-t-LacCer pretreatment. Scale bar, $5 \mu \mathrm{m}$. (C and D) Graphs showing the maximal fluorescence intensity after BDNF treatment normalized to the mean fluorescence in the pretreatment period $\left(F / F_{0}\right)$, with or without $L-t-L a c C e r$ pretreatment $(20 \mu \mathrm{M})$. The maximal $\mathrm{F} / \mathrm{F}_{0}$ was measured at 1 time point (C) and during a binned 3-min period (D) for both conditions. Data are the mean \pm s.e.m. (BDNF, $n=6$; BDNF plus $L-t$-LacCer pretreatment, $n=$ $8 ; * P<0.05$, t-test $)$.

Additional file 3: Figure S3-Total $\beta 1$-integrin surface levels are unaffected by treatments to disrupt $\beta 1$-integrin clustering or $\mathrm{Ca}^{2+}$ signaling. Quantification of $\beta 1$-integrin surface levels after vehicle (BSA), BDNF $(50 \mu \mathrm{g} / \mathrm{mL})$ alone, L-t-LacCer $(20 \mu \mathrm{M})$ alone and plus BDNF, the $\beta 1$ integrin function-blocking antibody ( $F \times n$ Blk $A b ; 5 \mu \mathrm{g} / \mathrm{mL}$ ) alone and plus BDNF, control antibody $(5 \mu \mathrm{g} / \mathrm{mL})$ alone and plus BDNF treatments. Data are the mean \pm s.e.m. $(n>50, n / s P>0.05$, ANOVA with Tukey's post hoc analysis).

Additional file 4: Figure S4-Total TrkB surface levels are unaffected by treatments to disrupt $\beta 1$-integrin clustering or $\mathrm{Ca}^{2+}$ signaling Quantification of TrkB surface levels after vehicle (BSA), BDNF $(50 \mu \mathrm{g} / \mathrm{mL})$ alone, L-t-LacCer $(20 \mu \mathrm{M})$ alone, L-t-LacCer plus BDNF, Fxn Blk Ab $(5 \mu \mathrm{g} /$ $\mathrm{mL}$ ) alone, Fxn Blk Ab plus BDNF, control antibody (5 $\mu \mathrm{g} / \mathrm{mL})$ alone, and control antibody plus BDNF treatments. Data are the mean \pm s.e.m. $(n>$ 50, n/s $P>0.05$, ANOVA with Tukey's post hoc analysis).

Additional file 5: Movie S1-BDNF-induced growth cone membrane expansion visualized through GFP-paxillin TIRF microscopy. Representative time-lapse movie of a Xenopus spinal neuron growth cone expressing GFP-paxillin. Uniform bath application of BDNF (50 $\mathrm{\mu g} /$ $\mathrm{mL}$; time 00:00) induced rapid membrane expansion. The TIRF images were collected every $1 \mathrm{~min}$ as indicated at the top left. Scale bar, $5 \mu \mathrm{m}$. Format: MOV (MPEG4 compression).

Additional file 6: Figure S5-BDNF-induced growth cone membrane expansion according to experimental treatments. (A) Representative live-cell phase images of the growth cone during the pre- and posttreatment period with either vehicle (BSA), BDNF $(50 \mu \mathrm{g} / \mathrm{mL})$ alone, and L-t-LacCer $(20 \mu \mathrm{M})$ plus BDNF. Dashed lines represent growth cone diameter measurement. Scale bar, $5 \mu \mathrm{m}$. (B) Quantification of the mean growth cone diameter during the pre- and post-treatment period with either vehicle (BSA), BDNF $(50 \mu \mathrm{g} / \mathrm{mL})$ alone, L-t-LacCer $(20 \mu \mathrm{M})$ plus $B D N F$, the $\beta 1$-integrin function-blocking antibody (Fxn Blk Ab; $5 \mu \mathrm{g} / \mathrm{mL}$ ) alone and plus BDNF, BAPTA-AM $\left(1 \mu \mathrm{M} ; 30 \mathrm{nM}\left[\mathrm{Ca}^{2+}\right]_{\mathrm{e}}\right)$ alone and plus BDNF. Data are the mean \pm s.e.m. $\left(n>50,{ }^{*} P<0.05\right.$, ANOVA with Tukey's post hoc analysis).

Additional file 7: Figure S6-Quality control analysis of $\beta 1$-integrin clustering after BDNF and MAG combination treatments. Growth cones from each experimental group in Figure 6B were randomly selected for quantification of $\beta 1$-integrin clustering reanalysis (Research Randomizer V. 3.0 software), using a range of fluorescence threshold values (two-, two and a half-, three- and four-fold above the background fluorescence). Data are the mean \pm s.e.m. $(n=50, * P<0.05, n / s P>0.05$ as compared to control, ANOVA with Tukey's post hoc analysis.)

Additional file 8: Figure S7-Graphical depiction of temporal treatment events for live-cell axon growth assays. Summary figure showing the time-course sequence of combination treatments with $L-t$ LacCer, the $\beta 1$-integrin function-blocking antibody (Fxn Blk Ab), BAPTA, $M A G$, and BDNF for the live cell axon growth rate assay used in Figures $3,4,5,6$.

\section{Abbreviations}

BDNF: brain-derived neurotrophic factor; BSA: bovine serum albumin; $\left[\mathrm{Ca}^{2+}\right]$ : intracellular $\mathrm{Ca}^{2+}$ concentration; D-e-LacCer: D-lactosyl- $\beta 1$-1'-N-octanoyl-Derythro-sphingosine; EGTA: ethylene glycol tetraacetic acid; FAK: focal adhesion kinase; GFP: green fluorescent protein; GSL: glycosphingolipid; L-tLacCer: $\beta$-D-lactosyl-N-octanoyl-L-threo-sphingosine; MAG: myelin-associated glycoprotein; TIRF microscopy: total internal reflection fluorescence microscopy.

\section{Acknowledgements}

We thank David Marks and the late Dick Pagano (Mayo Clinic) for insightful discussions and for the lipid probes; Jim Tarara, Zheyan Chen and Jarred Nesbitt for technical assistance; and members of the Henley lab for critical 
comments. We would also like to thank Ken Yamada (US National Institutes of Health) and Doug DeSimone (University of Virginia) for their generous gifts of antibodies to $\beta 1$-integrin and $\alpha 5$-integrin, respectively. This work was supported by a John M. Nasseff, Sr. Career Development Award in Neurologic Surgery Research from the Mayo Clinic $(J R H)$, career development funds from the Craig Neilsen Foundation (JRH), and the US National Institutes of Health $(J R H)$. A Robert D. and Patricia E. Kern Predoctoral Fellowship award supported JHH. A Langan MD/PhD Predoctoral Fellowship award supported LPC.

\section{Author details}

'Medical Scientist Training Program, Mayo Graduate School, Mayo Clinic: College of Medicine, Rochester, Minnesota 55905, USA. ${ }^{2}$ Department of Neurologic Surgery, Mayo Clinic: College of Medicine, Rochester, Minnesota 55905, USA. ${ }^{3}$ Department of Physiology and Biomedical Engineering, Mayo Clinic: College of Medicine, Rochester, Minnesota 55905, USA. ${ }^{4}$ Department of Pediatrics, University of Colorado Anschutz Medical Campus, Aurora, Colorado 80045, USA.

\section{Authors' contributions}

LPC, JHH and JRH conceived the project and designed experiments; LPC, $\mathrm{JHH}$ and SJH performed experiments and analyzed data; LPC and JRH wrote the manuscript; JRH supervised the project. All authors read and approved the final manuscript.

Received: 19 September 2011 Accepted: 30 November 2011 Published: 30 November 2011

\section{References}

1. Eastwood SL, Law AJ, Everall IP, Harrison PJ: The axonal chemorepellant semaphorin $3 \mathrm{~A}$ is increased in the cerebellum in schizophrenia and may contribute to its synaptic pathology. Mol Psychiatry 2003, 8:148-155.

2. Zikopoulos B, Barbas $\mathrm{H}$ : Changes in prefrontal axons may disrupt the network in autism. J Neurosci 2010, 30:14595-14609.

3. Chelly J: Breakthroughs in molecular and cellular mechanisms underlying X-linked mental retardation. Hum Mol Genet 1999, 8:1833-1838.

4. Goodman CS: Mechanisms and molecules that control growth cone guidance. Annu Rev Neurosci 1996, 19:341-377.

5. Tessier-Lavigne M, Goodman CS: The molecular biology of axon guidance. Science 1996, 274:1123-1133.

6. Burden-Gulley SM, Payne HR, Lemmon V: Growth cones are actively influenced by substrate-bound adhesion molecules. J Neurosci 1995 15:4370-4381.

7. Dickson BJ: Molecular mechanisms of axon guidance. Science 2002, 298:1959-1964

8. Itofusa $\mathrm{R}$, Kamiguchi $\mathrm{H}$ : Polarizing membrane dynamics and adhesion for growth cone navigation. Mol Cell Neurosci 2011, 48:332-338.

9. $\quad$ Ming G-L, Wong ST, Henley J, Yuan X-B, Song H-J, Spitzer NC, Poo M-M: Adaptation in the chemotactic guidance of nerve growth cones. Nature 2002, 417:411-418

10. Dent EW, Gertler FB: Cytoskeletal dynamics and transport in growth cone motility and axon guidance. Neuron 2003, 40:209-227.

11. Ramon y Cajal S: Degeneration and regeneration of the nervous system New York: Oxford University Press, American Branch; 1928.

12. Schwab ME, Bartholdi D: Degeneration and regeneration of axons in the lesioned spinal cord. Physiol Rev 1996, 76:319-370.

13. McKerracher L, David S, Jackson DL, Kottis V, Dunn RJ, Braun PE: Identification of myelin-associated glycoprotein as a major myelinderived inhibitor of neurite growth. Neuron 1994, 13:805-811.

14. Tang S, Woodhall RW, Shen YJ, DeBellard ME, Saffell JL, Doherty $P$ Walsh FS, Filbin MT: Soluble myelin-associated glycoprotein (MAG) found in vivo inhibits axonal regeneration. Mol Cell Neurosci 1997, 9:333-346.

15. Mukhopadhyay G, Doherty P, Walsh FS, Crocker PR, Filbin MT: A novel role for myelin-associated glycoprotein as an inhibitor of axonal regeneration. Neuron 1994, 13:757-767.

16. Hines $J H$, Abu-Rub $M$, Henley JR: Asymmetric endocytosis and remodeling of $\beta 1$-integrin adhesions during growth cone chemorepulsion by MAG. Nat Neurosci 2010, 13:829-837.

17. Bechara A, Nawabi H, Moret F, Yaron A, Weaver E, Bozon M, Abouzid K, Guan J-L, Tessier-Lavigne M, Lemmon V, Castellani V: FAK-MAPK- dependent adhesion disassembly downstream of $\mathrm{L} 1$ contributes to semaphorin3A-induced collapse. EMBO J 2008, 27:1549-1562.

18. Gatlin JC, Estrada-Bernal A, Sanford SD, Pfenninger KH: Myristoylated, alanine-rich C-kinase substrate phosphorylation regulates growth cone adhesion and pathfinding. Mol Biol Cell 2006, 17:5115-5130.

19. Niederöst B, Oertle T, Fritsche J, McKinney RA, Bandtlow CE: Nogo-A and myelin-associated glycoprotein mediate neurite growth inhibition by antagonistic regulation of RhoA and Rac1. J Neurosci 2002, 22:10368-10376

20. Hu F, Strittmatter SM: The N-terminal domain of Nogo-A inhibits cell adhesion and axonal outgrowth by an integrin-specific mechanism. $J$ Neurosci 2008, 28:1262-1269.

21. Niederöst BP, Zimmermann DR, Schwab ME, Bandtlow CE: Bovine CNS myelin contains neurite growth-inhibitory activity associated with chondroitin sulfate proteoglycans. J Neurosci 1999, 19:8979-8989.

22. Kiryushko D, Berezin V, Bock E: Regulators of neurite outgrowth: role of cell adhesion molecules. Ann N Y Acad Sci 2004, 1014:140-154

23. Serini G, Valdembri D, Zanivan S, Morterra G, Burkhardt C, Caccavari F, Zammataro L, Primo L, Tamagnone L, Logan M, Tessier-Lavigne M, Taniguchi M, Püschel AW, Bussolino F: Class 3 semaphorins control vascular morphogenesis by inhibiting integrin function. Nature 2003, 424:391-397.

24. Webb DJ, Parsons JT, Horwitz AF: Adhesion assembly, disassembly and turnover in migrating cells - over and over and over again. Nat Cell Biol 2002, 4:E97-100

25. Ezratty EJ, Partridge MA, Gundersen GG: Microtubule-induced focal adhesion disassembly is mediated by dynamin and focal adhesion kinase. Nat Cell Biol 2005, 7:581-590.

26. Myers JP, Santiago-Medina M, Gomez TM: Regulation of axonal outgrowth and pathfinding by integrin-ECM interactions. Dev Neurobiol 2011 71:901-923.

27. Arnaout MA, Mahalingam B, Xiong J-P: Integrin structure, allostery, and bidirectional signaling. Annu Rev Cell Dev Biol 2005, 21:381-410

28. Schwartz MA, Schaller MD, Ginsberg MH: Integrins: emerging paradigms of signal transduction. Annu Rev Cell Dev Biol 1995, 11:549-599.

29. Condic ML, Letourneau PC: Ligand-induced changes in integrin expression regulate neuronal adhesion and neurite outgrowth. Nature 1997, 389:852-856.

30. Ivins JK, Yurchenco PD, Lander AD: Regulation of neurite outgrowth by integrin activation. J Neurosci 2000, 20:6551-6560.

31. Schmid RS, Anton ES: Role of integrins in the development of the cerebral cortex. Cereb Cortex 2003, 13:219-224

32. Andrews MR, Czvitkovich S, Dassie E, Vogelaar CF, Faissner A, Blits B, Gage FH, ffrench-Constant C, Fawcett JW: Alpha9 integrin promotes neurite outgrowth on tenascin- $\mathrm{C}$ and enhances sensory axon regeneration. J Neurosci 2009, 29:5546-5557.

33. Blackmore $M$, Letourneau PC: L1, $\beta 1$ integrin, and cadherins mediate axonal regeneration in the embryonic spinal cord. J Neurobiol 2006, 66:1564-1583.

34. Lemons ML, Condic ML: Integrin signaling is integral to regeneration. Exp Neurol 2008, 209:343-352

35. Tan CL, Kwok JCF, Patani R, Ffrench-Constant C, Chandran S, Fawcett JW: Integrin activation promotes axon growth on inhibitory chondroitin sulfate proteoglycans by enhancing integrin signaling. J Neurosci 2011 31:6289-6295.

36. Pande $\mathrm{G}$ : The role of membrane lipids in regulation of integrin functions. Curr Opin Cell Biol 2000, 12:569-574.

37. Guan J-L: Cell biology. Integrins, rafts, Rac, and Rho. Science 2004 303.773-774

38. Humphries JD, Wang P, Streuli C, Geiger B, Humphries MJ, Ballestrem C: Vinculin controls focal adhesion formation by direct interactions with talin and actin. J Cell Biol 2007, 179:1043-1057.

39. Sydor AM, Su AL, Wang FS, Xu A, Jay DG: Talin and vinculin play distinct roles in filopodial motility in the neuronal growth cone. J Cell Biol 1996, 134:1197-1207.

40. Tadokoro S: Talin binding to integrin tails: a final common step in integrin activation. Science 2003, 302:103-106.

41. Chen $\mathrm{H}$, Choudhury DM, Craig SW: Coincidence of actin filaments and talin is required to activate vinculin. J Biol Chem 2006, 281:40389-40398.

42. Frame M, Norman J: A tal(in) of cell spreading. Nat Cell Biol 2008, 10:1017-1019. 
43. Robles E, Gomez TM: Focal adhesion kinase signaling at sites of integrinmediated adhesion controls axon pathfinding. Nat Neurosci 2006, 9:1274-1283.

44. Woo S, Rowan DJ, Gomez TM: Retinotopic mapping requires focal adhesion kinase-mediated regulation of growth cone adhesion. $J$ Neurosci 2009, 29:13981-13991.

45. Ghosh A, Carnahan J, Greenberg ME: Requirement for BDNF in activitydependent survival of cortical neurons. Science 1994, 263:1618-1623.

46. Conover JC, Erickson JT, Katz DM, Bianchi LM, Poueymirou WT, McClain J, Pan L, Helgren M, Ip NY, Boland P: Neuronal deficits, not involving motor neurons, in mice lacking BDNF and/or NT4. Nature 1995, 375:235-238.

47. Barde YA, Edgar D, Thoenen H: Purification of a new neurotrophic factor from mammalian brain. EMBO J 1982, 1:549-553.

48. Lindsay RM, Barde YA, Davies AM, Rohrer $\mathrm{H}$ : Differences and similarities in the neurotrophic growth factor requirements of sensory neurons derived from neural crest and neural placode. J Cell Sci Suppl 1985, 3:115-129

49. Gehler S, Shaw AE, Sarmiere PD, Bamburg JR, Letourneau PC: Brain-derived neurotrophic factor regulation of retinal growth cone filopodial dynamics is mediated through actin depolymerizing factor/cofilin. Neurosci 2004, 24:10741-10749.

50. Ip NY, Stitt TN, Tapley P, Klein R, Glass DJ, Fandl J, Greene LA, Barbacid M, Yancopoulos GD: Similarities and differences in the way neurotrophins interact with the Trk receptors in neuronal and nonneuronal cells. Neuron 1993, 10:137-149.

51. Pfenninger $\mathrm{KH}$ : Regulation of membrane expansion at the nerve growth cone. J Neurosci 2003, 116:1209-1217.

52. Grabham PW, Goldberg DJ: Nerve growth factor stimulates the accumulation of beta 1 integrin at the tips of filopodia in the growth cones of sympathetic neurons. J Neurosci 1997, 17:5455-5465.

53. Grabham PW, Foley M, Umeojiako A, Goldberg DJ: Nerve growth factor stimulates coupling of beta1 integrin to distinct transport mechanisms in the filopodia of growth cones. J Cell Sci 2000, 113(Pt 17):3003-3012.

54. Robles E, Woo S, Gomez T: Src-dependent tyrosine phosphorylation at the tips of growth cone filopodia promotes extension. J Neurosci 2005, 25:7669-7681.

55. Santiago-Medina M, Myers JP, Gomez TM: Imaging adhesion and signaling dynamics in Xenopus laevis growth cones. Dev Neurobiol 2011.

56. Kiss JZ, Troncoso E, Djebbara Z, Vutskits L, Muller D: The role of neural cell adhesion molecules in plasticity and repair. Brain Res Rev 2001, 36:175-184.

57. Lindsay RM: Nerve growth factors (NGF, BDNF) enhance axonal regeneration but are not required for survival of adult sensory neurons. J Neurosci 1988, 8:2394-2405.

58. Liu Y, Kim D, Himes BT, Chow SY, Schallert T, Murray M, Tessler A, Fischer I: Transplants of fibroblasts genetically modified to express BDNF promote regeneration of adult rat rubrospinal axons and recovery of forelimb function. J Neurosci 1999, 19:4370-4387

59. Kim D, Schallert T, Liu Y, Browarak T, Nayeri N, Tessler A, Fischer XXX, Murray M: Transplantation of genetically modified fibroblasts expressing BDNF in adult rats with a subtotal hemisection improves specific motor and sensory functions. Neurorehabil Neural Rep 2001, 15:141-150.

60. Spencer TK, Mellado W, Filbin MT: BDNF activates CaMKIV and PKA in parallel to block MAG-mediated inhibition of neurite outgrowth. $\mathrm{Mol}$ Cell Neurosci 2008, 38:110-116.

61. Leventhal PS, Shelden EA, Kim B, Feldman EL: Tyrosine phosphorylation of paxillin and focal adhesion kinase during insulin-like growth factor-Istimulated lamellipodial advance. J Biol Chem 1997, 272:5214-5218.

62. Choi CK, Vicente-Manzanares M, Zareno J, Whitmore LA, Mogilner A Horwitz AR: Actin and alpha-actinin orchestrate the assembly and maturation of nascent adhesions in a myosin II motor-independent manner. Nat Cell Biol 2008, 10:1039-1050.

63. Singh RD, Holicky EL, Cheng ZJ, Kim SY, Wheatley CL, Marks DL, Bittman R, Pagano RE: Inhibition of caveolar uptake, SV40 infection, and 1-integrin signaling by a nonnatural glycosphingolipid stereoisomer. J Cell Biol 2007, 176:895-901.

64. Wang GX, Poo M-M: Requirement of TRPC channels in netrin-1-induced chemotropic turning of nerve growth cones. Nature 2005, 434:898-904.

65. Duband JL, Dufour S, Yamada SS, Yamada KM, Thiery JP: Neural crest cell locomotion induced by antibodies to beta 1 integrins. A tool for studying the roles of substratum molecular avidity and density in migration. J Cell Sci 1991, 98(Pt 4):517-532.

66. Ming GL, Lohof AM, Zheng JQ: Acute morphogenic and chemotropic effects of neurotrophins on cultured embryonic Xenopus spinal neurons. J Neurosci 1997, 17:7860-7871.

67. Woo S, Gomez TM: Rac1 and RhoA promote neurite outgrowth through formation and stabilization of growth cone point contacts. J Neurosci 2006, 26:1418-1428.

68. Henley J, Poo M-M: Guiding neuronal growth cones using $\mathrm{Ca} 2+$ signals. Trends Cell Biol 2004, 14:320-330.

69. Hinkle PM, Kinsella PA, Osterhoudt KC: Cadmium uptake and toxicity via voltage-sensitive calcium channels. J Biol Chem 1987, 262:16333-16337.

70. Hong K, Nishiyama M, Henley J, Tessier-Lavigne M, Poo M: Calcium signalling in the guidance of nerve growth by netrin-1. Nature 2000 , 403:93-98.

71. Myers JP, Gomez TM: Focal adhesion kinase promotes integrin adhesion dynamics necessary for chemotropic turning of nerve growth cones. $J$ Neurosci 2011, 31:13585-13595.

72. Van Berkum MF, Goodman CS: Targeted disruption of $\mathrm{Ca}(2+)$-calmodulin signaling in Drosophila growth cones leads to stalls in axon extension and errors in axon guidance. Neuron 1995, 14:43-56.

73. Hanson PI, Schulman $\mathrm{H}$ : Neuronal $\mathrm{Ca} 2+/$ calmodulin-dependent protein kinases. Annu Rev Biochem 1992, 61:559-601.

74. Leeuwen FN, Kain HE, Kammen RA, Michiels F, Kranenburg OW, Collard JG The guanine nucleotide exchange factor Tiam1 affects neuronal morphology; opposing roles for the small GTPases Rac and Rho. J Cell Biol 1997, 139:797-807.

75. Fleming IN, Elliott CM, Buchanan FG, Downes $\mathrm{CP}$, Exton JH: Ca2 +/calmodulin-dependent protein kinase II regulates Tiam1 by reversible protein phosphorylation. J Biol Chem 1999, 274:12753-12758.

76. Farnsworth $\mathrm{CL}$, Freshney NW, Rosen LB, Ghosh A, Greenberg ME, Feig LA: Calcium activation of Ras mediated by neuronal exchange factor RasGRF. Nature 1995, 376:524-527.

77. Jin M, Guan C-B, Jiang Y-A, Chen G, Zhao C-T, Cui K, Song Y-Q, Wu C-P, Poo M-M, Yuan X-B: Ca2+-dependent regulation of rho GTPases triggers turning of nerve growth cones. J Neurosci 2005, 25:2338-2347.

78. Price LS, Langeslag M, Klooster ten JP, Hordijk PL, Jalink K, Collard JG: Calcium signaling regulates translocation and activation of Rac. J Biol Chem 2003, 278:39413-39421.

79. Fernández-Chacón R, Königstorfer A, Gerber SH, García J, Matos MF, Stevens CF, Brose N, Rizo J, Rosenmund C, Südhof TC: Synaptotagmin I functions as a calcium regulator of release probability. Nature 2001, 410:41-49.

80. Hakomori Sl: Cell adhesion/recognition and signal transduction through glycosphingolipid microdomain. Glycoconj J 2000, 17:143-151.

81. Zheng M, Fang H, Tsuruoka T, Tsuji T, Sasaki T, Hakomori S: Regulatory role of GM3 ganglioside in alpha 5 beta 1 integrin receptor for fibronectinmediated adhesion of FUA169 cells. J Biol Chem 1993, 268:2217-2222.

82. Isenberg G, Niggli V: Interaction of cytoskeletal proteins with membrane lipids. Int Rev Cytol 1998, 178:73-125.

83. Gomez TM, Harrigan D, Henley J, Robles E: Working with Xenopus spinal neurons in live cell culture. Meth Cell Biol 2003, 71:129-156.

84. Urbaniak G, Plous S: Research Randomizer.[http://www.randomizer.org/]

doi:10.1186/1741-7007-9-82

Cite this article as: Carlstrom et al:: Bidirectional remodeling of $\beta 1$ integrin adhesions during chemotropic regulation of nerve growth. BMC Biology 2011 9:82. 